Check for updates

Cite this: J. Mater. Chem. C, 2021. 9, 11882

Received 1st May 2021,

Accepted 3rd August 2021

DOI: $10.1039 / \mathrm{d} 1 \mathrm{tc0} 02019 f$

rsc.li/materials-c

\section{Excited state mechanisms in crystalline carbazole: the role of aggregation and isomeric defects $\dagger$}

\author{
Federico J. Hernández (D) and Rachel Crespo-Otero (D)*
}

\begin{abstract}
The molecule of carbazole $(\mathrm{Cz})$ is commonly used as a building block in organic materials for optoelectronic applications, acting as a light-absorbing, electron donor and emitting moiety. Crystals from $\mathrm{Cz}$ and its derivatives display ultralong phosphorescence at room temperature. However, different groups have reported inconsistent quantum efficiencies for the same compounds. In a recent experimental study by Liu et al. (Nat. Mater. 2021, 20, 175-180), the ultralong phosphorescence properties of $\mathrm{Cz}$ have been associated with the presence of small fractions of isomeric impurities from commercially available Cz. In this paper, we use state-of-the-art computational approaches to investigate light-induced processes in crystalline and doped $\mathrm{C} z$. We revisit the role of aggregation and isomeric impurities on the excited state pathways and analyse the mechanisms for exciton, Dexter energy transfer and electron transport based on Marcus and Marcus-Levich-Jortner theories. Our excited state mechanisms provide a plausible interpretation of the experimental results and support the formation of charge-separated states at the defect/Cz molecular interface. These results contribute to a better understanding of the factors that enhance the excited state lifetimes in organic materials and the role of doping with organic molecules.
\end{abstract}

\section{Introduction}

The field of organic optoelectronics has experienced significant growth in the last few decades. The development of novel organic luminophores, commonly, aggregated structures of $\pi$-conjugated materials in the solid phase, has boosted the design of new materials for technologies such as photovoltaics, solid-state lasers, phototherapy, molecular sensing, optical imaging, and spintronics, amongst others. ${ }^{1-6}$ Since some of these applications benefit from long-lived excited states, achieving high populations of triplet states presents significant advantages.

Metal-free organic chromophores have low spin-orbit couplings (SOCs) limiting the efficiency of intersystem crossing (ISC). However, different strategies can be implemented to promote ISC including designing donor-acceptor systems with small singlet-triplet gaps and molecules with electron transitions that involve a change in the character of the states such as $\mathrm{n}-\pi^{*}$ transitions (El-Sayed rule). ${ }^{7}$ Other pathways include heavyatom and halogen substitution as well as crystal engineering. ${ }^{8-10}$

The discovery of several pure organic room-temperature phosphorescence (RTP) materials, displaying excited state lifetimes of over $100 \mathrm{~ms}$ in the crystalline phase, has attracted

Department of Chemistry, Queen Mary University of London, London, UK.

E-mail: r.crespo-otero@qmul.ac.uk

$\dagger$ Electronic supplementary information (ESI) available. See DOI: 10.1039/ d1tc02019f significant attention due to their promising applications. ${ }^{11-17}$ Despite the recent experimental and theoretical efforts in this direction, the mechanisms behind ultralong organic phosphorescence (UOP) are yet to be fully understood.

Because of its extensive $\pi$-conjugation and easy derivatisation, $\mathrm{Cz}$ is a common building block in molecular materials for optoelectronic applications, acting as a light-absorbing, electron donor and emitting moiety. ${ }^{1,8,18}$ Molecular crystals from pure $\mathrm{Cz}$ and its derivatives display UOP at room temperature. ${ }^{8,19}$ However, there are inconsistencies in the values of the lifetimes and quantum yields reported by different groups. ${ }^{20}$ In a recent study, Liu et al. explored the role of isomeric defects in the UOP mechanism of $\mathrm{Cz}$. The authors detected that the small fractions of $1 H$-benzo $[f]$ indole (Bd, Fig. 1) found in commercial $\mathrm{Cz}$ are responsible for the ultralong lifetimes of the excited states. The isomeric defects serve as microplanar heterojunctions facilitating the formation of charge-separated states. ${ }^{20}$

In organic semiconductors, defects enable the formation of localised carrier states acting as traps for electrons and holes. ${ }^{21}$ The controlled use of defects to tune excited state lifetimes represents a promising opportunity in the field of functional electronic materials, which has been recently exploited for other organic systems demonstrating that this phenomenon is not exclusive to $\mathrm{Cz}^{22}$ To better understand the mechanism of formation of long-lived triplets in Cz crystals, we investigate the processes activated by light and the role of isomeric defects. We start by examining the mechanism following a localised excitation on the embedded monomers. We analyse the exciton 


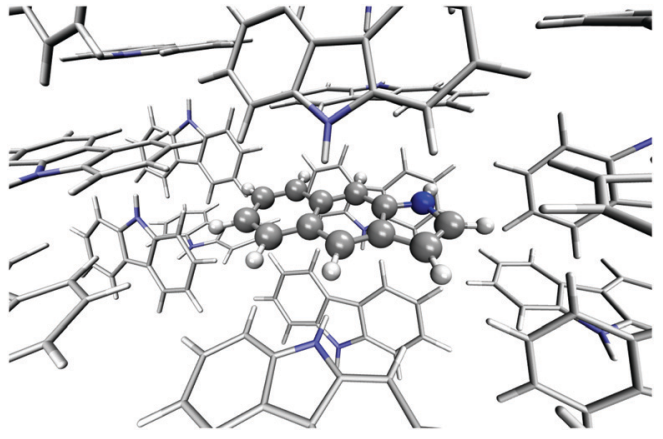

Fig. 1 Isomeric defect of $\mathrm{Bd}(1 \mathrm{H}$-benzo[f]indole) highlighted with ball and stick representation.

states and transport and evaluate the role of $\mathrm{H}$-dimerisation in deactivation processes. We then investigate the formation of charge-transfer states in pure and doped crystalline $\mathrm{Cz}$ and the effect of isomeric defects of Bd on the excited state pathways. Our simulations help understand light-activated processes in crystalline $\mathrm{Cz}$ with implications in the design of new electronic materials for a broad range of applications.

\section{Computational methods}

The crystal structure of $\mathrm{Cz}$, obtained from the CCDC (CCDC number: 1525166), was optimised with periodic DFT using Quantum Espresso. ${ }^{23}$ These calculations were done using the PBE-D2 functional with a plane wave cut-off of 40 Ry and ensuring Monkhorst-Pack $k$-point convergence $(2 \times 1 \times 2)$.

To simulate the excited states in the molecular crystal, we created cluster models of $\mathrm{Cz}$ and applied the QM-QM' ONIOM schemes implemented in fromage. ${ }^{24,25}$ The QM regions included either one or two molecules of $\mathrm{Cz}$ simulated at the (TD-)B3LYP/6-311++G(d,p) level of theory using Gaussian $16 .{ }^{26}$ We tested different functionals including long-range corrected functionals with optimal tuning. The B3LYP functional showed the best agreement with the experiments (Section S1, ESI $\dagger$ ). The cluster models considered 16 molecules for the case of one molecule in the QM region and 27 or 28 molecules for the QM regions including dimers. The $\mathrm{QM}^{\prime}$ region was described using the density functional tight-binding formalism as implemented in the DFTB+ package. $^{27}$

The minima for the $S_{0}, S_{1}, S_{2}$ and $T_{1}$ states were optimised using the ONIOM Embedded Cluster model (OEC). The geometries of the $\mathrm{T}_{3} / \mathrm{T}_{2}$ and $\mathrm{S}_{2} / \mathrm{S}_{1}$ crossings were optimised with a penalty function ${ }^{28}$ with the condition of a zero energy gap. To explore the excited state mechanisms, we generated linear interpolated pathways based on the Cartesian coordinates of the stationary points (for example, between FC and $S_{1 \text { min }}, T_{3 \min }, T_{3} / T_{2}, T_{2 \text { min }}$ and $T_{1 \text { min }}$ ).

The effect of the long-range electrostatic interactions was addressed using the ONIOM Ewald Embedded Cluster (OEEC) model. ${ }^{24}$ For the electrostatic embedding at the higher level of theory, we use RESP charges obtained at the same level of theory. For the embedding of the lower level of theory, the charges were obtained with $\mathrm{PBE} / 6-31 \mathrm{G}(\mathrm{d})$. Because long-range
Coulomb interactions (model OEEC) do not have a significant effect on the energies (see Section S3, ESI $\dagger$ ), we focus our discussion on the results obtained using the OEC model.

The probability of a radiative transition $k_{\text {if }}$ (and the corresponding radiative lifetime from state $i, \tau_{\mathrm{i}}$ ) between an initial state $\left|\Psi_{\mathrm{i}}\right\rangle$ and a final state $\left|\Psi_{\mathrm{f}}\right\rangle$ can be calculated using Fermi's Golden rule: ${ }^{29}$

$$
k_{\mathrm{if}}(\omega)=\frac{4 \omega^{3} n^{2}}{3 \hbar c^{3}}\left|\left\langle\Psi_{\mathrm{i}}|\hat{\mu}| \Psi_{\mathrm{f}}\right\rangle\right|^{2} \delta\left(E_{\mathrm{i}}-E_{\mathrm{f}} \pm \hbar \omega\right),
$$

where $\omega$ is the frequency of the photon, $n$ is the refractive index of the medium, $\hbar$ is the Planck constant divided by $2 \pi, c$ is the speed of light in vacuum, $\mu$ is the electric transition dipole moment operator, and $E_{j}$ is the energy of the state $j$. We considered a refractive index of $n=1.781$ for the crystal. ${ }^{30}$ For fluorescence, $\vec{\mu}_{i \rightarrow \mathrm{f}}=\left\langle\mathrm{S}_{n}|\hat{\mu}| \mathrm{S}_{0}\right\rangle$, where $\mathrm{S}_{n}$ is the emitting state, and in most cases $n=1$ (Kasha's rule).

In the case of phosphorescence, $\left\langle\mathrm{T}_{m}|\hat{\mu}| \mathrm{S}_{0}\right\rangle$ can be approximated using the first-order perturbation theory to include the spin-orbit coupling operator $\hat{H}_{\text {SOC }}$ allowing intensity borrowing from spinallowed transitions. ${ }^{31}$ This approximation converges slowly with the number of excited states and significant errors can be obtained even when hundreds of excited states are included. ${ }^{32,33}$ In this work, we use instead the multiconfigurational quadratic response (MCQR) method, which provides reliable values for $\mu_{\mathrm{T}_{m} \rightarrow \mathrm{S}_{0}}{ }^{33}$ These calculations were performed at the TD-B3LYP/6-311++G(d,p) level of theory using the Dalton software. ${ }^{34,35}$

Herein, we estimate the rate constants for nonradiative electron transfer (ET) processes as intersystem crossing (ISC), and transport processes like exciton and charge transfer using the semiclassical Marcus theory as

$$
k_{\mathrm{ET}}=\frac{2 \pi}{\hbar}\left|H_{\mathrm{ab}}\right|^{2} \frac{1}{\sqrt{4 \pi \lambda k_{\mathrm{B}} T}} \exp \left(-\frac{\left(\Delta G^{\circ}+\lambda\right)^{2}}{4 \lambda k_{\mathrm{B}} T}\right),
$$

where $\mathrm{T}$ is the absolute temperature, $k_{\mathrm{B}}$ is the Boltzmann constant, $\lambda$ is the reorganisation energy and $\Delta G^{\circ}$ stands for the variation of the adiabatic Gibbs free energy during the process. $H_{\mathrm{ab}}$ is the electronic coupling term between the diabatic states involved in the ET process.

For ISC, $H_{\mathrm{ab}}=\left\langle\mathrm{S}_{n}\left|\boldsymbol{H}_{\mathrm{SOC}}\right| \mathrm{T}_{m}\right\rangle$, where $\mathrm{S}_{n}$ and $\mathrm{T}_{m}$ are the singlet and triplet states involved in the $\mathrm{S}_{n} \rightarrow \mathrm{T}_{m}$ nonradiative transition. The reorganisation energy was approximated as $\lambda \approx E_{\mathrm{T}_{m}}\left(R_{\min \mathrm{S}_{n}}\right)-$ $E_{\mathrm{T}_{m}}\left(R_{\min _{\mathrm{T}}}\right)$, as it has been done in previous studies. ${ }^{36}$ The spinorbit couplings (SOCs) were evaluated at the TD-B3LYP/ $6-311++\mathrm{G}(\mathrm{d}, \mathrm{p})$ level of theory adopting the Breit-Pauli spinorbit Hamiltonian with effective charge approximation as implemented in the PySOC package. ${ }^{37}$

The ET rate coefficients were also calculated using the Marcus-Levich-Jortner (MLJ) equation as implemented in ref. 38 and 39:

$$
k_{\mathrm{ET}}=\frac{2 \pi}{\hbar}\left|H_{\mathrm{ab}}\right|^{2} F_{k},
$$

where $F_{k}$ is the final vibrational state density at the point of the initial state energy level weighted by Franck-Condon factors. The vibrational modes with frequencies well above $210 \mathrm{~cm}^{-1}$ 
$\left(k T_{300 \mathrm{~K}}\right)$ and the highest reorganisation energies were considered as quantum modes $q_{j}$ as explained in Section S2 of the ESI. $\dagger$ The Huang-Rhys factors and reorganisation energies were calculated using the DUSHIN code. ${ }^{40}$

For the calculation of the fluorescence time constant $\left(\tau_{\mathrm{f}}\right)$ and quantum yield $\left(\Phi_{\mathrm{f}}\right)$, we analysed the processes depleting the population of $S_{1}$ including internal conversion $\left(k_{\mathrm{IC}}\right)$ and intersystem crossing $\left(k_{\mathrm{ISC}}\right)$. Experiments showed that internal conversion to the ground state is negligible with respect to $k_{\text {ISC }}$ $\left(k_{\mathrm{IC}} \ll k_{\mathrm{ISC}}\right){ }^{41,42}$ This is in line with the large gap between $\mathrm{S}_{1}$ and $S_{0}$. We calculated the rates of intersystem crossing from $S_{1}$ considering the transitions to $\mathrm{T}_{4}, \mathrm{~T}_{3}, \mathrm{~T}_{2}$ and $\mathrm{T}_{1}$. However, the transition $\mathrm{S}_{1} \rightarrow \mathrm{T}_{3}$ accounted for $99.9 \%$ of the total value. More information about the calculations of $\tau_{\mathrm{f}}$ and $\Phi_{\mathrm{f}}$ can be found in Section S4 of the ESI $\dagger$.

For the calculation of the exciton hopping rates of the singlet and triplet states, the coupling terms $\left(H_{\mathrm{ab}}=J_{i j}^{\mathrm{S}}\right.$ and $H_{\mathrm{ab}}=J_{i j}^{\mathrm{T}}$ ) were evaluated using the half energy splitting method. The coupling terms used to evaluate the energy transfer rates of triplets $\left(H_{\mathrm{ab}}^{\mathrm{T}}\right)$ or charge hopping rates $\left(H_{\mathrm{ab}}^{\mathrm{CT}}\right)$ were computed using constrained DFT with configuration interactions (CDFTCI) as implemented in Q-Chem. ${ }^{43}$ The active space considered for the CDFT-CI calculations of the couplings between the triplets was $\left\{\left|\mathrm{S}_{0} \mathrm{~S}_{0}\right\rangle,\left|\mathrm{S}_{0} \mathrm{~T}_{1}\right\rangle,\left|\mathrm{T}_{1} \mathrm{~S}_{0}\right\rangle\right\}$. For the calculation of the charge transfer between negatively charged $\left(\mathrm{Cz}^{-}\right)$and neutral molecules, the active space compromised the following states: $\left\{\left|\mathrm{S}_{0} \mathrm{Cz}^{-}\right\rangle,\left|\mathrm{Cz}^{-} \mathrm{S}_{0}\right\rangle\right\}$. To analyse the performance of these methods, additional single point calculations were performed using the ADC(2)/TZVP level of theory with point charge embedding as implemented in Turbomole. ${ }^{44}$

We have also estimated the diffusion constant in the singlet or triplet state as

$$
D=\frac{k_{i j} R_{i j}^{2}}{z},
$$

where $k_{i j}$ is the exciton hopping rate coefficient between the donor $i$ and the acceptor $j, R_{i j}$ is the distance between the centres of mass of $i$ and $j$, and $z$ is a parameter equal to 2, 4 or 6 for one-, two- and three-dimensional diffusion, respectively. Eqn (4) was derived considering nearest neighbour random walk hopping in an isotropic medium for a cubic cell. ${ }^{45}$ Herein, we use it to provide a qualitative comparison between transport in singlet and triplet states. The diffusion length was calculated as

$$
L_{\mathrm{D}}=\sqrt{D \tau}
$$

where $\tau$ is the fluorescence or phosphorescence lifetime.

\section{Results and discussion}

Given the weak nature of intermolecular interactions in molecular organic crystals, localised excitations and incoherent exciton transfer are common mechanisms at room temperature. ${ }^{46}$ We have considered the formation of excited species localised on monomers and dimers in the $\mathrm{Cz}$ crystal as the initial step in the excited state mechanism. In the next section, we explore the excited state mechanism following the excitation of a single monomer in the crystal environment.

\subsection{The molecule centred mechanism}

To understand the excited state processes, we explored the linear interpolated pathway between the ground state and the excited state minima and also evaluated the SOCs between the triplets and $S_{1}$ (Fig. 2). There is a good agreement between the calculated energies at the TD-B3LYP/6-311++G(d,p) level of theory and the experimental data (Table S3, ESI $\dagger$ ). ${ }^{18,19,20,47}$ A value of $3.73 \mathrm{eV}$ is obtained for the $\mathrm{S}_{0} \rightarrow \mathrm{S}_{1}$ absorption energy of a cluster including 6 molecules of $\mathrm{Cz}$ in contrast with the experimental value of $3.62 \mathrm{eV}$.

The experimental oscillator strength for the $S_{0} \rightarrow S_{2}$ transition in the gas phase is an order of magnitude greater than that for $\mathrm{S}_{0} \rightarrow \mathrm{S}_{1}{ }^{41}$ A similar trend is observed in the solid state. ${ }^{18,19}$ Depending on the initial energy, either the $S_{1}$ or the brightest $S_{2}$ state can be populated. Provided initial excitation to $\mathrm{S}_{1}$, the system will follow vibrational relaxation in the picosecond scale to $\mathrm{S}_{1 \text { min }}$ from which fluorescence can compete with non-radiative mechanisms and processes like exciton transfer (see Section 3.2). Experiments in the gas phase using jet-cooled molecular beams do not show phosphorescence or nonradiative decay to $\mathrm{S}_{0}\left(\phi_{\mathrm{f}} \approx 1\right) .{ }^{41}$ However, ISC is the main non-radiative pathway from $S_{1}$ in the condensed phases. ${ }^{19,20,42}$

The fluorescence lifetime $\left(\tau_{\mathrm{f}}\right)$ of $\mathrm{Cz}$ in solution under an inert atmosphere or dispersed in a solid matrix is around 14-15 ns, with a quantum yield of $\Phi_{\mathrm{f}}=0.4-0.6$. When $\mathrm{Cz}$ is dissolved in organic media under an air saturated atmosphere, $\tau_{\mathrm{f}}=7.7-8.8 \mathrm{~ns}$ with $\Phi_{\mathrm{f}}=0.28-0.48 .^{42} \mathrm{In}$ the crystalline phase, $\tau_{\mathrm{f}}=8.2 \mathrm{~ns}$ at $300 \mathrm{~K}$ with a $\Phi_{\mathrm{f}}=0.78{ }^{18}$ For the pure crystal, we obtained fluorescence lifetimes of 11.1 and 7.9 ns and fluorescence quantum yields of

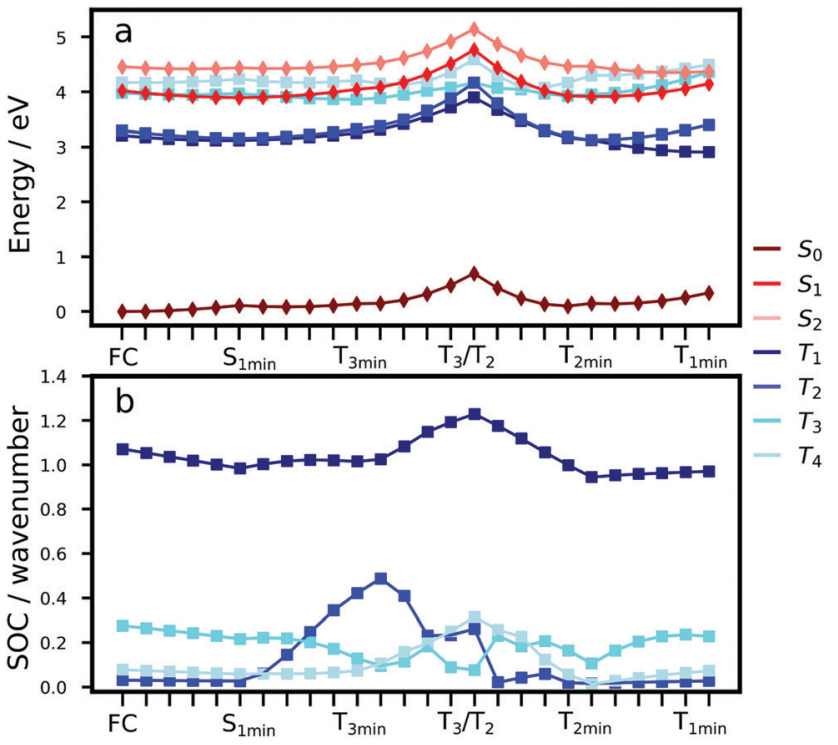

Fig. 2 (a) Linear interpolated Cartesian coordinate (LICC) pathway from the Franck-Condon ( $F C$ ) geometry, to $S_{1}$, to the excited state minima (OEC model, TD-B3LYP/6-311++G(d,p)). (b) Spin-orbit coupling values along the LICC pathway. 
Table 1 Fluorescence lifetime $\left(\tau_{f}\right)$ and quantum yield $\left(\Phi_{f}\right)$. Phosphorescence lifetime $\left(\tau_{p}\right) . k_{\mid S C}$, was calculated using eqn (2). The values in brackets were obtained using eqn (3)

\begin{tabular}{lll}
\hline & Predicted & Experimental \\
\hline$\tau_{\mathrm{f}}$ & $11.1(7.9) \mathrm{ns}$ & $8.2-11.5 \mathrm{~ns}^{18,19}$ \\
$\Phi_{\mathrm{f}}$ & $0.76(0.55)$ & $0.78^{18}$ \\
$\tau_{p}$ & $7.2(7.2) \mathrm{s}$ & $1.11 \mathrm{~s}^{a 18}$ \\
$k_{\mathrm{ISC}}$ & $2.14 \times 10^{7}\left(5.75 \times 10^{7}\right) \mathrm{s}^{-1}$ & $3.87 \times 10^{7} \mathrm{~s}^{-1 b 42}$
\end{tabular}

${ }^{a}$ Measured in a solid matrix at $4 \mathrm{~K}$. The value at $300 \mathrm{~K}$ is $0.852 \mathrm{~s}$. ${ }^{b}$ Measured in a solid matrix at $77 \mathrm{~K}$.

0.76 and 0.55 considering the Marcus and MLJ models, respectively. These values are in excellent agreement with the experimental ones (Table 1), which indicates that ISC is the most important competing pathway.

At the $S_{1}$ minimum, the SOCs are smaller than $1 \mathrm{~cm}^{-1}$, which is not surprising in the light of the El-Sayed rule given the $\pi-\pi^{*}$ character of all states involved. However, if the energy gaps between the states of different multiplicities are small, ISC can happen even for small SOCs. ${ }^{48}$ Our values are in line with those reported by Ma et al. for $\mathrm{Cz}^{.9}{ }^{49}$ The SOCs between $\mathrm{S}_{1}$ and $\mathrm{T}_{n=1,2,3}$ remain almost unaltered between the $\mathrm{FC}$ and $\mathrm{S}_{1 \text { min }}$ geometries (Fig. 2b). Due to the similar energies of $S_{1}$ and $T_{3}$ $\left(\Delta E_{\mathrm{S}_{1}-\mathrm{T}_{3}}=0.07 \mathrm{eV}\right)$, direct intersystem crossing is likely to occur (Fig. 2a). While the SOC values with $\mathrm{T}_{1}$ are almost 4 times greater than those with $\mathrm{T}_{3}$, a large energy gap $(0.77 \mathrm{eV})$ prevents the occurrence of ISC to $T_{1}$. The rates for the $S_{1} \rightarrow T_{3}$ transition calculated using the Marcus and MLJ equations are $2.1410^{7} \mathrm{~s}^{-1}$ and $5.75 \times 10^{7} \mathrm{~s}^{-1}$, respectively. These values are in line with the ISC rate of $3.87 \times 10^{7} \mathrm{~s}^{-1}$ obtained in a solid matrix of isopropanol-ethyl ether and the rates obtained for $\mathrm{Cz}$ derivatives in the solid state (Table 1$){ }^{18,42}$

The existence of a region for the crossing between both surfaces $\left(T_{3} / T_{2}\right)$ promotes internal conversion from $T_{3}$ to $T_{2}$. The optimised geometry of the crossing shows a slight out-ofplane distortion from one of the aromatic rings (Fig. S6, ESI $\dagger$ ). After the crossing, the population can split into two branches (right or left, Fig. 2), resulting in either phosphorescence or nonradiative decay. The band associated with phosphorescence from $T_{1 \text { min }}$ appears at $2.25 \mathrm{eV}^{18}$ (calculated value: $2.57 \mathrm{eV}$ ).

Crystalline $\mathrm{Cz}$ also shows a phosphorescence sideband at $2.95 \mathrm{eV}$, in very good agreement with the predicted emission from $\mathrm{T}_{2}$ found at $2.98 \mathrm{eV} .^{19}$ This band becomes more intense when the crystal is electronically excited at energies over the $S_{1}$ excitation energy $(3.62 \mathrm{eV}) \cdot{ }^{19}$ Initial excitation to $\mathrm{S}_{2}$ could be followed by either IC to $\mathrm{S}_{1}$, the most likely pathway, or ISC to $\mathrm{T}_{4}$. The linear interpolated pathway considering relaxation from $\mathrm{S}_{2}$ is shown in Fig. S5 (ESI $\dagger$ ). An appreciable vibronic coupling has been observed between $S_{2}$ and $S_{1}$ states in the gas-phase ${ }^{41}$ and solid state as well. ${ }^{50}$ We have also located an accessible $\mathrm{S}_{2} / \mathrm{S}_{1}$ crossing, which can help facilitate IC (Fig. S5 and S6, ESI $\dagger$ ). Once in $S_{1}$, the system can explore the relaxation pathways described before. Our estimated value of the ISC rate for the $\mathrm{S}_{2} \rightarrow \mathrm{T}_{4}$ transition is $k_{\mathrm{ISC}}^{\mathrm{S}_{2}}=7.3 \times 10^{7} \mathrm{~s}^{-1}$ which is just 3.3 times greater than $k_{\mathrm{ISC}}^{\mathrm{S}_{1}}$. At the $\mathrm{S}_{2 \mathrm{~min}}$ structure, $\mathrm{S}_{2}$ and $\mathrm{T}_{4}$ have very similar energies $\left(\Delta E_{\mathrm{S}_{2}-\mathrm{T}_{4}}=-0.008 \mathrm{eV}\right)$.
Once the system is in the lowest energy triplet manifold, provided the excess of vibrational energy, the molecule will be able to explore the left brand for a longer time allowing phosphorescence emission at higher energies $(2.98 \mathrm{eV})$, which explains the sideband in the phosphorescence spectrum. The energies of $T_{1}$ and $T_{2}$ are almost degenerate and very close to the energy of the $T_{2}$ minimum. Non-Kasha phosphorescence has been also observed for analogue systems based on dibenzothiophene, where a sideband shifted to blue from the $\mathrm{T}_{1}$ emission band was unambiguously assigned to the emission from $\mathrm{T}_{2}{ }^{.1}$

\subsection{Exciton processes}

3.2.1 Dimers: is $\mathbf{H}$-aggregation relevant? H-aggregation has been hypothesised as the reason for the stabilisation of longlived triplet states in crystalline $\mathrm{Cz}$ and UOP materials in general. ${ }^{19,52}$ The $\mathrm{Cz}$ molecule crystallises in a herringbone packing motif (Fig. 3). ${ }^{47}$ Herein, we investigate how the aggregation patterns affect the excited state mechanism of crystalline Cz.

We have identified six different dimers (A-F, Fig. 3). Dimers $\mathrm{A}, \mathrm{B}$, and C have been previously reported. ${ }^{19,20}$ Dimers A, B, and $\mathrm{E}$ show edge-to-face arrangements commonly found in herringbone crystals, while dimers $\mathrm{C}$ and $\mathrm{D}$ are slipped $\pi$-stacking face-to-face structures. Dimer F is planar displaying a close H. . . H contact at $3.19 \AA$. Table 2 displays the splitting of the first excited state into the excitonic states $S_{1}$ and $S_{2}$. A very small red-shift of the absorption energy is predicted. For the singlet states, $S_{1}$ and $S_{2}$ are excitonic states. The largest exciton couplings are obtained for dimers B $\left(4 \times 10^{-3} \mathrm{eV}\right)$ and $\mathrm{C}\left(2.3 \times 10^{-2} \mathrm{eV}\right)$ (Tables 2 and 3$)$.

Using the spectroscopic classification based on the oscillator strength values, the dimers can be classified as H- (D, E and F) or J-aggregates (A, B and C). The $\mathrm{H}$-aggregates are obtained when $f_{\mathrm{S}_{2}}>f_{\mathrm{S}_{1}}$ and J-aggregates when $f_{\mathrm{S}_{1}}>f_{\mathrm{S}_{2}}$. Previous studies on the effect of $\mathrm{H}$-aggregation in UOP organic materials have considered the classical Kasha's exciton model, ${ }^{19,52}$ which is based on the analysis of Coulombic interactions between two chromophores:

$$
J_{\text {Coul }}=\frac{\boldsymbol{\mu}_{1} \cdot \boldsymbol{\mu}_{2}-3\left(\boldsymbol{\mu}_{1} \cdot \hat{R}\right)\left(\boldsymbol{\mu}_{2} \cdot \hat{R}\right)}{4 \pi \varepsilon R^{3}},
$$

where $\boldsymbol{\mu}_{i}$ is the transition dipole moment (TDM) vector of the molecule " $i$ ", $\vec{R}=R \hat{R}$ is the intermolecular displacement vector connecting the centres of mass of the monomers, and $\varepsilon$ is the optical dielectric constant of the medium. For co-planar TDM vectors, the angle $\theta$ is defined as the angle between $\vec{R}$ and the TDM vector of any of the chromophores, and $J_{\text {Coul }}$ is given by

$$
J_{\text {Coul }}=\frac{\mu^{2}\left(1-3 \cos ^{2} \theta\right)}{4 \pi \varepsilon R^{3}} .
$$

From eqn ( 7 ) emerges the $\mathrm{H} / \mathrm{J}$ classification based on the magic angle $\theta=54.7^{\circ}$, i.e., $\mathrm{J}$-aggregates are formed if $0^{\circ}<\theta<54.7^{\circ}$ and $\mathrm{H}$-aggregates if $54.7^{\circ}<\theta<90.0^{\circ}$, which is strictly valid for systems with co-planar TDMs. ${ }^{53}$ The transition dipole moments for dimers $\mathrm{A}$ and $\mathrm{B}$ are oblique and define different planes (Fig. 3). Because of this, the spectroscopic classification of 

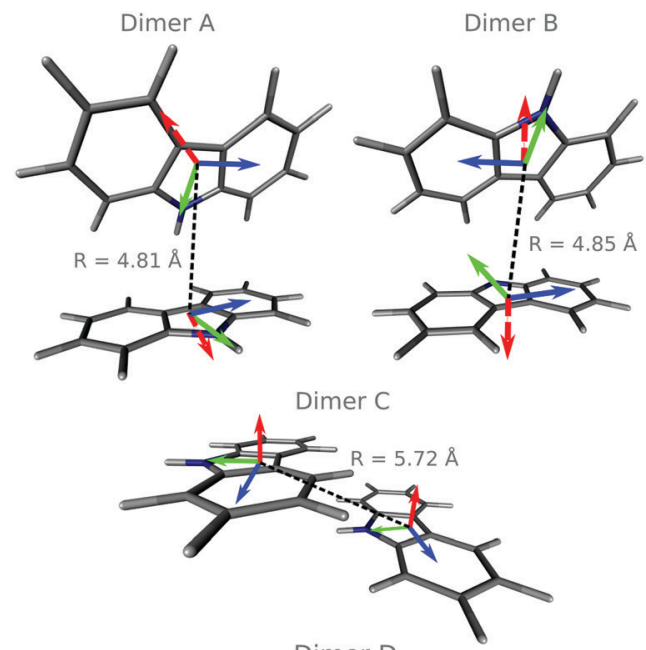

Dimer D
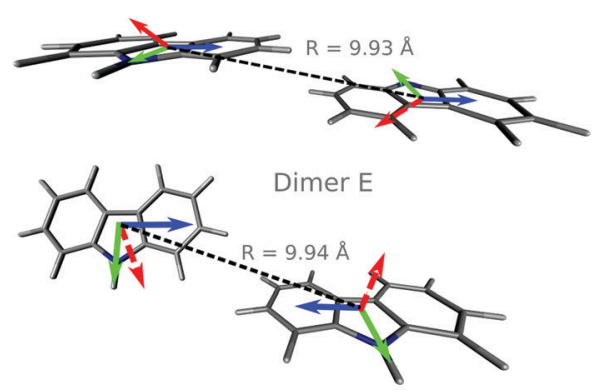

Dimer $\mathrm{F}$

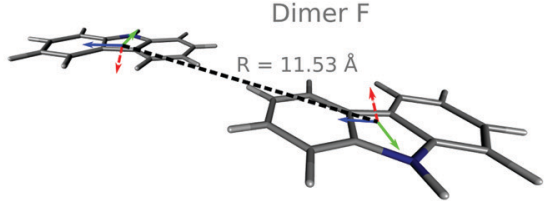

Fig. 3 Molecular dimers in the Cz crystal optimised at the TD-B3LYP/ $6-311++G(d, p)$ level using the OEC model. Distances between the centres of mass $(R)$ are also shown. The green, blue and red arrows represent the transition dipole moments of the $\mathrm{S}_{0} \rightarrow \mathrm{S}_{1}, \mathrm{~S}_{0} \rightarrow \mathrm{S}_{2}$ and $\mathrm{T}_{1} \rightarrow \mathrm{S}_{0}$ transitions, respectively. The arrow lengths are not proportional to the transition dipole magnitudes.

Table 2 Photophysical properties of the six different dimer motifs present in the crystal packing of carbazole. $E_{\mathrm{S}_{1}}$ and $E_{\mathrm{S}_{2}}$ are the absorption energies of the lower and upper states produced by exciton splitting, respectively. $f_{\mathrm{S}_{1}}$ and $f_{\mathrm{S}_{2}}$ are the corresponding oscillator strengths. The aggregates were classified spectroscopically according to their oscillator strengths. The angle $\theta$ was evaluated at the respective $S_{0}$ equilibrium geometry of each dimer

\begin{tabular}{llllllll}
\hline Dimer & $E_{\mathrm{S}_{1}}(\mathrm{eV})$ & $f_{\mathrm{S}_{1}}$ & $E_{\mathrm{S}_{2}}(\mathrm{eV})$ & $f_{\mathrm{S}_{2}}$ & Aggregate & \multicolumn{2}{c}{$\theta$} \\
\cline { 5 - 8 } & & & & & & Mon 1 & Mon 2 \\
\hline $\mathrm{A}$ & 4.010 & 0.032 & 4.011 & 0.016 & $\mathrm{~J}$ & $28.9^{\circ}$ & $79.7^{\circ}$ \\
$\mathrm{B}$ & 4.001 & 0.032 & 4.009 & 0.012 & $\mathrm{~J}$ & $26.5^{\circ}$ & $77.1^{\circ}$ \\
$\mathrm{C}$ & 3.972 & 0.077 & 4.019 & 0.001 & $\mathrm{~J}$ & $27.8^{\circ}$ & $26.7^{\circ}$ \\
$\mathrm{D}$ & 4.021 & 0.000 & 4.023 & 0.058 & $\mathrm{H}$ & $83.0^{\circ}$ & $83.1^{\circ}$ \\
$\mathrm{E}$ & 4.018 & 0.018 & 4.020 & 0.044 & $\mathrm{H}$ & $72.0^{\circ}$ & $77.6^{\circ}$ \\
$\mathrm{F}$ & 4.019 & 0.000 & 4.020 & 0.063 & $\mathrm{H}$ & $57.1^{\circ}$ & $57.1^{\circ}$ \\
\hline
\end{tabular}

dimers A and B does not agree with that obtained with the Kasha's angle (Table 2). For F, the TDMs are co-planar either; however, in this case the angle $\theta$ is close to the magic angle of 54.7.

The exchange interactions not considered in Kasha's model could be relevant for these dimers with intermolecular distances of around $3 \AA$ (Fig. S8, ESI $\dagger$ ). Close packing arrangements are susceptible to experiencing a significant wave function overlap and therefore short-range interactions as exchange or superexchange. The magnitude of the shortrange coupling can be comparable to or even exceed the Coulomb coupling. These interactions can promote a different exciton behaviour than normally associated with Kasha's $\mathrm{H} / \mathrm{J}$-aggregates, ${ }^{54}$ and thus the conventional geometric classification is incomplete at best.

In the case of the triplet states for the dimers A, B, C and E, the lowest energy states are localised and we could not find exciton states. For the dimers $\mathrm{D}$ and $\mathrm{F}$, where the states $\mathrm{T}_{1}-\mathrm{T}_{6}$ are excitonic, the values of $J$ are smaller than $2.5 \times 10^{-4} \mathrm{eV}$ except for the $\mathrm{T}_{5}-\mathrm{T}_{6}$ splitting with $J_{\mathrm{T}_{5} \mathrm{~T}_{6}}=1.0 \times 10^{-3} \mathrm{eV}$. We optimised the geometries of the $T_{1}$ and $S_{1}$ states of all dimers in the crystal environment. In line with the experimental observations, the predicted phosphorescence from $\mathrm{T}_{1}$ is an out-of-plane polarised transition (Fig. 3). ${ }^{55}$ Dimerisation has a minimal effect on the energy of the $\mathrm{T}_{1} \rightarrow$ $\mathrm{S}_{0}$ transition and the corresponding phosphorescence lifetimes (see Table S7, ESI $\dagger$ ). The SOC values between $\mathrm{S}_{1}$ and triplet states with lower or similar energies are not considerably increased with respect to the monomer (Tables S4 and S6, $\mathrm{ESI} \dagger)$. Hence, no increase in the ISC rate constant is expected via direct SOC due to the presence of dimers though the number of ISC channels could be greater.

For embedded dimers, the $\mathrm{T}_{1} \rightarrow \mathrm{S}_{0}$ transition densities are localised on single molecules. A significant degree of localisation is also found for a cluster of six $\mathrm{Cz}$ molecules, all of them being treated quantum mechanically (Fig. S10, ESI $\dagger$ ). Our calculations show that $\mathrm{H} / \mathrm{J}$-aggregation does not have a relevant effect on the energies or lifetimes of the triplet states of $\mathrm{Cz}$. In the next section, we analyse the implications of the localisation of the excitations for different transport regimes for singlets and triplets in pure crystalline $\mathrm{Cz}$.

3.2.2 Exciton transport. Exciton transfer competes with radiative and nonradiative molecule-centred processes in the molecular crystals. Exciton transport can proceed via coherent or incoherent hopping. In the latter case, it occurs mainly via Coulomb coupling which in its most simple form can be modelled by eqn (6), obtaining a $R^{-6}$ decay of the hopping rate. ${ }^{56}$ Due to the lower concentration of triplets and their weak exciton couplings in $\mathrm{Cz}$, triplet diffusion is likely to proceed through a Dexter energy transfer (triplet-singlet) instead of a triplet-triplet diffusion process. Triplet diffusion is not theoretically limited to $100-200 \mathrm{~nm}$ as in singlet excitons because the SOCs, which determine the triplet lifetimes, do not govern the transport of triplets. ${ }^{57}$

To evaluate the rates of singlet exciton transport and triplet energy transfer in $\mathrm{Cz}$ crystals, we have considered the exciton coupling rates between adjacent molecules using the Marcus and MLJ models (eqn (2) and (3)). Table 3 shows the exciton 
Table 3 Exciton couplings $\left(J_{i j}\right)$, exciton hopping rate coefficients $\left(k_{i j}\right)$, diffusion constants $(D)$ and diffusion lengths $\left(L_{D}\right)$ computed for the six dimers present in the crystal packing using eqn (2), (4) and (5), respectively, at the TD-B3LYP/6-311++G(d,p) level of theory. The values in brackets are obtained by computing $k_{i j}$ with eqn (3)

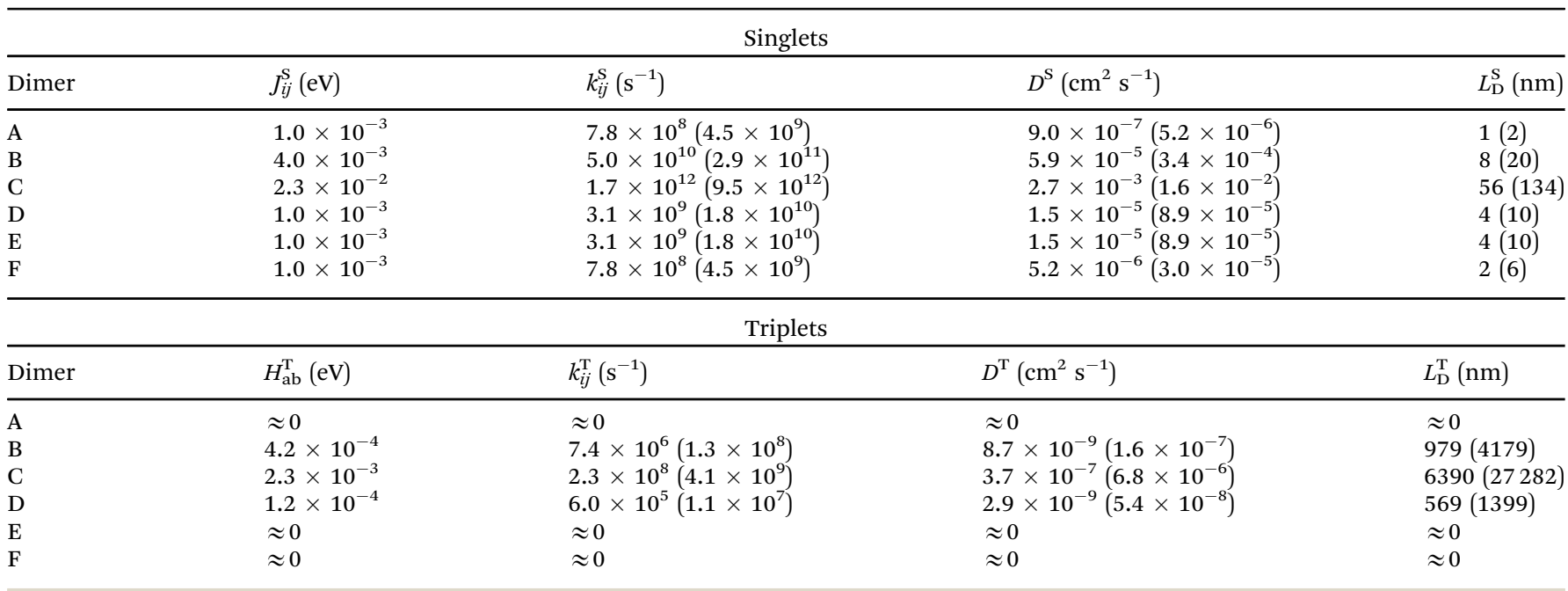

hopping rates $k_{i j}$, diffusion coefficients $D$ and diffusion lengths $L_{\mathrm{D}}$ for $\mathrm{S}_{1}$ and $\mathrm{T}_{1}$ at $298 \mathrm{~K} . D$ and $L_{\mathrm{D}}$ are obtained with eqn (4) and (5), respectively, using the distances between monomers shown in Fig. 3 and the experimental radiative lifetimes (Table 1). For both singlets and triplets, the hopping rate coefficients are systematically greater when the MLJ model is used. This shows the active role of vibrations in the exciton hopping process because the process is accompanied by a concomitant molecular distortion, i.e. the motion should have a polaronic character and thermally activated diffusion could be important.

The total reorganisation energy for exciton transfer in $\mathrm{S}_{1}$ is $\lambda=0.246 \mathrm{eV}$, which corresponds to an approximate barrier of $\lambda / 4=0.062 \mathrm{eV}$ for the exciton hopping between adjacent molecules. This barrier is larger than the values of exciton couplings for all dimers. Thus, a significant localisation of the singlet excitation is expected and exciton transport should proceed through an incoherent hopping mechanism. In our calculations, six modes with frequencies of $670,1035,1307$, 1337, 1371 and $1661 \mathrm{~cm}^{-1}$ associated with in-plane bending and stretching vibrations of the $\mathrm{C}-\mathrm{C} / \mathrm{C}=\mathrm{C} / \mathrm{C}=\mathrm{N}$ bonds of the $\pi$ conjugated ring had the highest Huang-Rhys factors and were treated as quantum modes (see Section S2 and Fig. S7, ESI†). The largest value of $J$ is obtained for dimer $\mathrm{C}$ due to its $\pi$-stacking structure. For dimer $\mathrm{C}, k_{i j}$ is comparable to the value obtained for the analogue slipped $\pi$-stacked dimer of anthracene, which also features a herringbone structure and an incoherent exciton transport mechanism. ${ }^{39}$

Fig. 4 shows possible exciton transfer paths through the dimers with the shortest intermolecular distances (A, B and C). The predicted exciton rate coefficients (Table 3 ) indicate that the only process likely to compete with vibrational relaxation to $\mathrm{S}_{1 \text { min }}$ (taking $h \nu_{\mathrm{vib}}=10^{3} \mathrm{~cm}^{-1}$ leads to $2 \pi / \nu_{\mathrm{vib}}=2 \times 10^{-13} \mathrm{~s}$ ) is exciton transport along dimer C. Exciton hopping through dimer B involves further transfer through dimer A (Fig. 4a), which has a very small exciton coupling and hence a small hopping rate coefficient. The 1-D diffusion coefficients and diffusion lengths obtained considering exciton transport in $\mathrm{S}_{1}$ for dimer $\mathrm{C}$ are $2.7 \times 10^{-3} \mathrm{~cm}^{2} \mathrm{~s}^{-1}$ and $134 \mathrm{~nm}$, respectively, in qualitative agreement with the experimentally and computationally reported values for pure anthracene crystals. ${ }^{39}$ Exciton transport is also anisotropic in anthracene, where the slipped $\pi$-stacked dimer similar to dimer $\mathrm{C}$ also shows higher diffusion constant and length. ${ }^{39}$

In the case of $T_{1}$, the rates were calculated considering $\lambda=$ $0.643 \mathrm{eV}$ and the normal mode with $\omega_{k}=1661 \mathrm{~cm}^{-1}$ with the highest Huang-Rhys factor (Fig. S7, ESI $\dagger$ ), which involves the in-plane stretching vibration of the $\mathrm{C}-\mathrm{C} / \mathrm{C}=\mathrm{C} / \mathrm{C}=\mathrm{N}$ bonds of the ring. Due to their lower couplings and higher reorganisation energies, dimers B, C, and D show hopping rates three orders of magnitude smaller in $T_{1}$ than in $S_{1}$ (see Table 3). The small couplings in dimers A, E and F are caused by a small overlap between the constituent monomers, preventing any energy transfer in these directions (see Fig. 4a).

Due to the spin-forbidden nature of phosphorescence, triplets exhibit lifetimes on the order of milliseconds for many

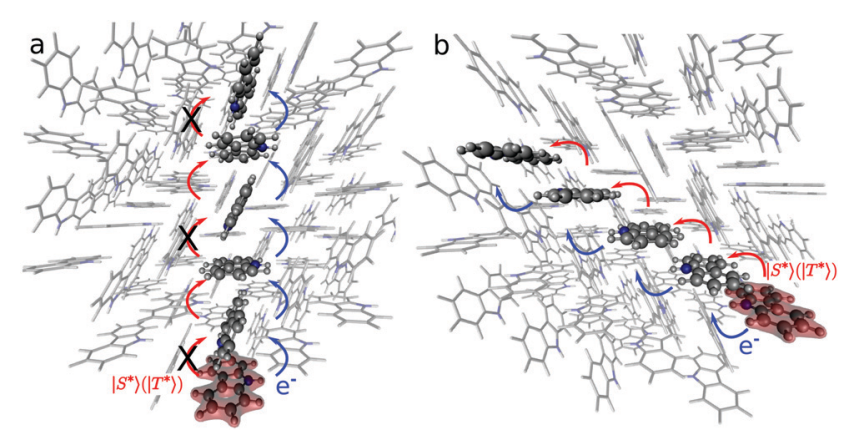

Fig. 4 Schematic representation of two possible exciton transport pathways involving dimers A and B (a), or dimer C (b). The highlighted molecule represents the initial position for electron $\left(e^{-}\right.$, in blue) or exciton $\left(\left|S^{\star}\right\rangle\right.$ or $\left|T^{\star}\right\rangle$ ) transport (in red). The crosses indicate specific pathways that are less likely due to the small values of the couplings. 
of the pure organic materials with potential use in optoelectronics, or even longer as it is the case of $\mathrm{Cz}(1.1 \mathrm{~s}){ }^{18}$ The longer lifetime compensates the slow velocity yielding a much longer diffusion length for triplet excitons reaching lengths of tens of $\mu \mathrm{m}$ as shown in Table 3. Taking dimer $\mathrm{C}$ as an example, the diffusion constant in $\mathrm{T}_{1}$ is $D=6.8 \times 10^{-6} \mathrm{~cm}^{2} \mathrm{~s}^{-1}, 4$ orders lower than that in $S_{1}$, and two orders lower than the reported value for anthracene $D=(0.5-2) \times 10^{-4} \mathrm{~cm}^{2} \mathrm{~s}^{-1}$. However, the diffusion length estimated for dimer $\mathrm{C}$ is $27 \mu \mathrm{m}, 200$ times greater than $L_{\mathrm{D}}$ in $S_{1}$ and comparable to the value measured in anthracene crystals $\left(L_{\mathrm{D}}=7-20 \mu \mathrm{m}\right) .{ }^{56}$ This huge increase comes from the long phosphorescence lifetime of $\mathrm{T}_{1}$ for $\mathrm{Cz}$ (see eqn (5)) (for anthracene $\tau_{\mathrm{p}}=23 \mathrm{~ms}$ ). ${ }^{58}$

The long lifetime of triplets in $\mathrm{Cz}$ enables delayed fluorescence via triplet-triplet annihilation (TTA). Considering the $k_{i j}$ of dimer $\mathrm{C}$ and no trapping or quenching, a triplet can visit $4.5 \times 10^{9}$ molecules in its lifetime period $\left(1.1 \times 10^{5}\right.$ for a singlet). However, the generation of triplets is limited by the slower $k_{\text {ISC }}$ which is three times lower than $k_{\mathrm{f}}$ (Table 1$)$. Dopants can be used to facilitate ISC, for example, $N, N$-di( $9 H$-fluoren-2yl)phenanthrene-3-amine (DFAP) has been successfully used to increase triplet-triplet annihilation delayed fluorescence (TTADF) in fluorene crystals. ${ }^{59}$

The rate equation of the concentration of triplets $[\mathrm{T}]$ is

$$
\frac{\partial[\mathrm{T}]}{\partial t}=G_{\mathrm{T}}+\left(k_{\mathrm{r}}+k_{\mathrm{nr}}\right)[\mathrm{T}]+\gamma_{\mathrm{TTA}}[\mathrm{T}]^{2},
$$

where $G_{\mathrm{T}}$ is the rate of the generation of triplets, $\left(k_{\mathrm{r}}+k_{\mathrm{nr}}\right)$ is the sum of the radiative and nonradiative decay constants of the triplet states, and $\gamma_{\text {TTA }}$ is the bimolecular annihilation constant which is related to the triplet diffusion coefficient D via the Smoluchowski theory of bimolecular reactions:

$$
\gamma_{\mathrm{TTA}}=4 \pi R_{\mathrm{a}} D
$$

where $R_{\mathrm{a}}$ is the annihilation radius calculated as the average distance between two excitons undergoing annihilation.

Under the condition of a continuous generation of triplets ( $G_{\mathrm{T}}=$ const), the steady-state solution of eqn (8) produces two different regimes. ${ }^{56}$ At a low excitation power density $\left(k_{r}+\right.$ $\left.k_{\mathrm{nr}}\right)[\mathrm{T}] \gg \gamma_{\mathrm{TTA}}[\mathrm{T}]^{2}$ and $[\mathrm{T}] \propto G_{\mathrm{T}}$, the spontaneous decay governs the dynamics of excitons, whereas for high densities more triplet excitons are produced, $\gamma_{\mathrm{TTA}}[\mathrm{T}]^{2} \gg\left(k_{\mathrm{r}}+k_{\mathrm{nr}}\right)[\mathrm{T}]$ and $[\mathrm{T}] \propto \sqrt{G_{\mathrm{T}}}$. Especially interesting is the power density at which $\left(k_{r}+k_{\mathrm{nr}}\right)[\mathrm{T}]=\gamma_{\mathrm{TTA}}[\mathrm{T}]^{2}$ because it represents the threshold at which the TTA process starts dominating the exciton dynamics. This power density threshold can be estimated from the material photophysical constants as

$$
G_{\mathrm{th}}=\frac{1}{\gamma_{\mathrm{TTA}} \tau^{2}}
$$

where $\tau$ is the lifetime of the excitation.

Eqn (10) indicates that exciton-exciton annihilation becomes more important as the exciton lifetime is longer. Considering dimer $\mathrm{C}$, the bimolecular annihilation constant estimated for $\mathrm{Cz}$ is $\gamma_{\mathrm{TTA}}=4.9 \times 10^{-12} \mathrm{~cm}^{3} \mathrm{~s}^{-1}$. This value is comparable with the reported value for anthracene crystals $\gamma_{\text {TTA }}=2.1-2.4 \times 10^{-11} \mathrm{~cm}^{3} \mathrm{~s}^{-1} \cdot{ }^{60}$ Despite the low bimolecular annihilation constant, $\mathrm{Cz}$ presents a remarkably long phosphorescence lifetime which can yield a small $G_{\text {th }}$ to produce TTADF using relatively low powers. Delayed fluorescence has been observed for pure $\mathrm{Cz}$ crystals, ${ }^{20}$ but no systematic investigation of the effect of the temperature or the light power density has been reported so far.

\subsection{Isomeric impurities}

Liu et al. showed that very low concentrations of $\mathrm{Bd}$ (even $0.1 \mathrm{~mol} \%$ ), an impurity commonly present in commercial $\mathrm{Cz}$, display UOP at room temperature. ${ }^{20}$ Direct excitation and transport of singlets and triplets in the $\mathrm{Cz}$ crystal can enable the charge separation at $\mathrm{Cz} / \mathrm{Bd}$ molecular junctions. Herein, we evaluate how the presence of $\mathrm{Bd}$ isomeric defects can affect the excited state mechanism of $\mathrm{Cz}$ in the solid state.

In our calculations, we considered $\mathrm{Bd}-\mathrm{Cz}$ dimers created by substituting a $\mathrm{Cz}$ molecule by a $\mathrm{Bd}$ molecule and reoptimised the geometries of the ground and excited states using the OEC method. The inclusion of long-range interactions (OEEC model) has a minimal effect on the energies of the excited states (Table S10, ESI $\dagger$ ). Because of the alignment of the energy levels of $\mathrm{Cz}$ and $\mathrm{Bd}$, the $\mathrm{CT}$ state where $\mathrm{Cz}$ acts as an electron acceptor from $\mathrm{Bd}\left(\mathrm{Cz}^{-} \mathrm{Bd}^{+}\right)$is more stable than the $\left(\mathrm{Cz}^{+} \mathrm{Bd}^{-}\right)$ state (Tables S9 and S11, ESI $\dagger$ ). ${ }^{20}$ To analyse the role of the $\mathrm{Cz}^{-} \mathrm{Bd}^{+}$states in the electron transfer process, we optimised these states using the CDFT method for dimers with smaller distances between the centres of mass (A-C).

Our calculations show that the presence of the $\mathrm{Bd}$ impurities redshifted the fluorescence emission energy of $\mathrm{Cz}$ around $33 \mathrm{~nm}$ (Table 4) which is in line with the $54 \mathrm{~nm}$ obtained experimentally. Both the $S_{1}$ and $T_{1}$ minima of the embedded $\mathrm{Cz}-\mathrm{Bd}$ dimers show a significant localisation of the excitation on the Bd moiety (Fig. S12-S14, ESI $\dagger$ ). The calculated absorption of the $\mathrm{Cz}-\mathrm{Bd}$ dimers at $3.5 \mathrm{eV}$ agrees with the onset absorption signal observed after HPLC of commercial $\mathrm{Cz}$, which has been attributed to $\mathrm{Bd}^{20}$

The predicted fluorescence band of the $\mathrm{Cz}-\mathrm{Bd}$ dimers appeared at 3.14-3.16 eV within the region where delayed emission of $\mathrm{Cz}$ doped with $\mathrm{Bd}$ has been observed (354-543 nm). ${ }^{20}$ For dimers $\mathrm{A}$ and $\mathrm{B}$, the energy gap between the $\mathrm{Cz}^{-} \mathrm{Bd}^{+}$state and the ground state is around $3 \mathrm{eV}$, which is also in the same region. We explored the mechanism of formation of $\mathrm{Cz}^{-} \mathrm{Bd}^{+}$ states at the $\mathrm{Cz}-\mathrm{Bd}$ molecular junction using the energy profiles based on different excited state minima for dimers A-C. Herein, we focus on the analysis of dimer A (Fig. 5), and the energy profiles for dimers A-C are shown in Fig. S12-S14 (ESI $\dagger$ ), respectively.

Table 4 Absorption and emission energies (in eV) for dimers A, B and C obtained with TD-B3LYP/6-311++G(d,p) using the OEC model

\begin{tabular}{llll}
\hline Transition & Dimer A & Dimer B & Dimer C \\
\hline $\mathrm{S}_{0} \rightarrow \mathrm{S}_{1}$ & 3.51 & 3.50 & 3.50 \\
$\mathrm{~S}_{1} \rightarrow \mathrm{S}_{0}$ & 3.14 & 3.16 & 3.16 \\
$\mathrm{~T}_{1} \rightarrow \mathrm{S}_{0}$ & 1.58 & 1.60 & 1.60
\end{tabular}


For pure crystalline $\mathrm{Cz}$, we have already discussed the monomer-centred mechanism in Section 3.1. Based on the localisation of the excitations and the energy profiles for the $\mathrm{Cz}$ dimers, we expect similar deactivation mechanisms. In this section, we analysed these decay pathways in doped dimers $(\mathrm{Cz}-\mathrm{Bd})$ contrasting them with the behaviour of pure $\mathrm{Cz}$. The mechanism for the $\mathrm{Cz}$ dimers starts with the excitation to one of the exciton states $\left(S_{1}-S_{4}\right)$, and analogously to the molecule-centred mechanism, vibrational relaxation is likely to stabilise the excitation in $\mathrm{S}_{1}$. For all dimers, $\mathrm{S}_{1}$ is clearly localised on one of the $\mathrm{Cz}$ monomers. In the case of $\mathrm{Cz}-\mathrm{Bd}$, for all dimers, the excitations obtained for the Franck-Condon and $S_{1}$ minima are localised on Bd. Once in $S_{1}$, the systems will emit light or nonradiative decay processes will be activated including exciton transport (Section 3.2.2) and charge transfer.

Decay to the triplet manifold through ISC is highly likely. For pure $\mathrm{Cz}$, given the proximity in energy with $\mathrm{T}_{5}$ and $\mathrm{T}_{6}$ and their similar SOCs (0.36 and $0.26 \mathrm{~cm}^{-1}$, respectively) the transition could occur to any of these states (Table S6, ESI $\dagger$ ). For doped $\mathrm{Cz}$, at the $\mathrm{S}_{1}$ geometry, the $\mathrm{T}_{2}, \mathrm{~T}_{3}$ and $\mathrm{T}_{4}$ states are almost resonant with $\mathrm{S}_{1}$ making ISC very likely. For $\mathrm{B}$ and $\mathrm{C}$, the largest SOCs are obtained for $\mathrm{T}_{3}\left(0.53\right.$ and $0.45 \mathrm{~cm}^{-1}$, respectively) and in the case of $A$ for $\mathrm{T}_{4}\left(0.92 \mathrm{~cm}^{-1}\right)$. The SOCs are slightly larger than those obtained for pure $\mathrm{Cz}$, which suggests that the impurity could help ISC. Following the population of the triplets, internal conversion will take the system to the localised $\mathrm{T}_{1}$ state.

3.3.1 Charge transfer states. From the $S_{1}$ minima, another possible mechanism is the formation of charge separated states. For dimer A, the energy of the optimised $\mathrm{Cz}^{-} \mathrm{Cz}^{+}$state in the singlet state is nearly resonant to the initial excitation energy, while accessing the $\mathrm{Cz}^{-} \mathrm{Cz}^{+}$triplet requires surpassing a classical inaccessible energy barrier of around $0.4 \mathrm{eV}$. Similarly, for both dimers B and C, the barriers to access the triplets are very high and classically forbidden, provided initial excitation to the lower singlet manifold. While increasing the initial

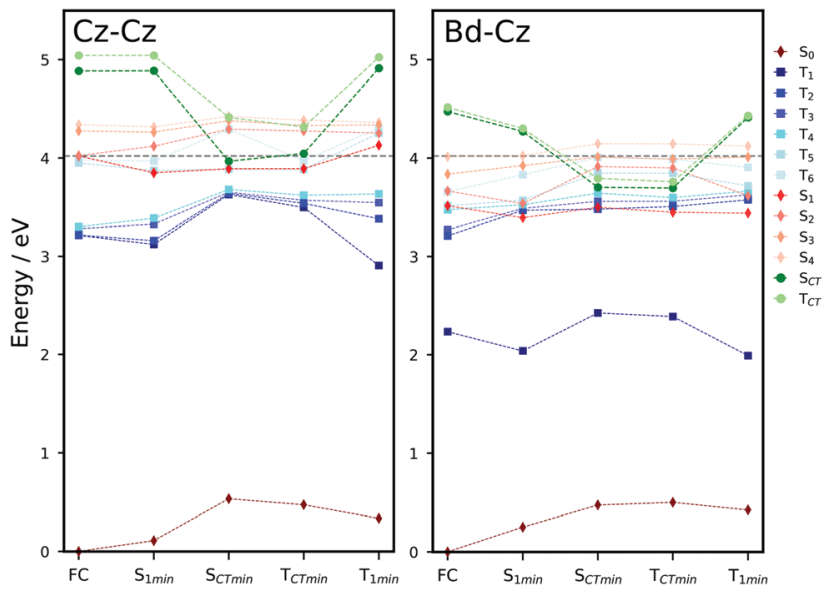

Fig. 5 Energy profiles for singlet and triplet states, including the $\mathrm{Cz}^{-} \mathrm{Cz}^{+}$ and $\mathrm{Cz}^{-} \mathrm{Bd}^{+}$charge transfer states $\left(\mathrm{S}_{\mathrm{CT}}\right.$ and $\left.\mathrm{T}_{\mathrm{CT}}\right)$ computed at the critical points for dimer $A$ embedded in the crystal environment using the OEC model. excitation energy or the temperature can allow populating these states, recombination is very likely. Due to the high energy of the $\mathrm{Cz}^{-} \mathrm{Cz}^{+}$state, other decay mechanisms will dominate.

How does the picture change for the $\mathrm{Cz}-\mathrm{Bd}$ molecular junctions? Both the singlet and triplet $\mathrm{Cz}^{-} \mathrm{Bd}^{+}$states are significantly more stable than in pure Cz. For the Bd doped dimers $\mathrm{A}$ and $\mathrm{B}$, the energies of the $\mathrm{Cz}^{-} \mathrm{Bd}^{+}$states at their optimised geometry are below the reference excitation energy for any of the $\mathrm{S}_{1}-\mathrm{S}_{4}$ states. Small amplitude vibrational distortions allowed in the crystalline phase facilitate the access to $\mathrm{Cz}^{-} \mathrm{Bd}^{+}$states swiftly when an isomeric defect is nearby. For dimer $\mathrm{C}, \mathrm{Cz}^{-} \mathrm{Bd}^{+}$singlets and triplets are above the initial excitation energy and will require additional energy to become accessible. Given the longer lifetime of triplet states, it is highly probable for the electron transfer to happen from the triplet state.

While the energy of the optimised geometry for the $\mathrm{Cz}^{-} \mathrm{Bd}^{+}$ state is slightly higher than that for $\mathrm{S}_{1}$, charge separation can occur because the rate of charge transfer involving $\mathrm{Cz}^{-}$for dimers A-D is in the order of vibrational relaxation (Table 5). The mechanism involves the formation of $\mathrm{Cz}^{-} \mathrm{Bd}^{+}$states associated with dimer $\mathrm{A}$ or $\mathrm{B}$, followed by charge separation. The $\mathrm{Bd}^{+}$radical cations can get trapped by the defects but $\mathrm{Cz}^{-}$ can transport across the crystal $\left(\mathrm{Cz}^{-}+\mathrm{Cz}=\mathrm{Cz}+\mathrm{Cz}^{-}\right)$. Our calculated rates (Table 5) indicate that charge separation is faster for dimer $\mathrm{C}\left(1.7 \times 10^{15} \mathrm{~s}^{-1}\right.$, MLJ value $)$, followed by dimer $\mathrm{A}\left(4.1 \times 10^{14} \mathrm{~s}^{-1}\right)$ and dimers D and B $\left(4.1 \times 10^{14}\right.$ and $7.9 \times$ $10^{13} \mathrm{~s}^{-1}$, respectively). Fig. 4 shows some possible pathways for electron transfer after the formation of the $\mathrm{Cz}^{-}$polarons. These processes keep the excitation alive for longer times contributing to the UOP.

The overall energy makeup indicates that the presence of isomeric impurities helps charge separation allowing the formation of negatively charged polarons $\left(\mathrm{Cz}^{-}\right)$. In the experimental work, the absorption band at 460-472 nm (2.6-2.7 eV) has been assigned to the $\mathrm{Cz}^{-}$species. ${ }^{20}$ Our calculations of the embedded $\mathrm{Cz}^{-}$have the excitation with a higher oscillator strength predicted around $2.1 \mathrm{eV}$ (2.3 eV with ADC(2)/TZVP, Table S12, ESI $\dagger$ ).

For dimer A embedded in point charges, we compared the energy levels of the $\mathrm{Cz}^{-} \mathrm{Cz}^{+}$and $\mathrm{Cz}^{-} \mathrm{Bd}^{+}$geometries optimised at CDFT-B3LYP/6-311++G(d,p) with those calculated with ADC(2)/TZVP (Table S11, ESI $\dagger$ ). For example, the energy gaps between the optimised $\mathrm{Cz}^{-} \mathrm{Bd}^{+}$state and the ground state are 3.87 and $3.85 \mathrm{eV}$ for $\mathrm{ADC}(2) / \mathrm{TZVP}$ and CDFT-B3LYP/

Table 5 Charge transfer $\mathrm{Cz}^{-} \rightarrow \mathrm{Cz}$ rate coefficients computed for the embedded dimers A-F using eqn (2) and (3) for the values shown in brackets

\begin{tabular}{ll}
\hline Dimer & $k_{\mathrm{CT}}^{\mathrm{CZ}^{-} \rightarrow \mathrm{Cz}}\left(\mathrm{s}^{-1}\right)$ \\
\hline $\mathrm{A}$ & $7.6 \times 10^{13}\left(4.1 \times 10^{14}\right)$ \\
$\mathrm{B}$ & $1.4 \times 10^{13}\left(7.9 \times 10^{13}\right)$ \\
$\mathrm{C}$ & $3.2 \times 10^{14}\left(1.7 \times 10^{15}\right)$ \\
$\mathrm{D}$ & $2.4 \times 10^{13}\left(1.3 \times 10^{14}\right)$ \\
$\mathrm{E}$ & $5.5 \times 10^{12}\left(3.0 \times 10^{13}\right)$ \\
$\mathrm{F}$ & $6.8 \times 10^{11}\left(3.7 \times 10^{12}\right)$
\end{tabular}


6-311++G(d,p), respectively. Both methods confirm that both the singlets and triplets of the $\mathrm{Cz}^{-} \mathrm{Bd}^{+}$state are accessible provided initial excitation energy to $\mathrm{S}_{1}$. In the case of $\mathrm{Cz}-\mathrm{Cz}$ dimers, these states are higher in energy, which explain why charge transfer states have not been observed in pure crystalline Cz.

\section{Conclusions}

Carbazole and its derivatives have applications in organic functional materials with long-lived excited states and ultralong phosphorescence. Due to the contradictory values of efficiencies and quantum yields obtained for materials synthesised by different groups, the interpretation of the processes underlying the UOP in $\mathrm{Cz}$ has been under debate. ${ }^{20}$ In this paper, we explore in detail the light-activated pathways in pure crystalline carbazole and $\mathrm{Cz}$ doped with $\mathrm{Bd}$. In contrast with previously proposed mechanisms based on $\mathrm{H}$-aggregation, ${ }^{19,52}$ we found that $\mathrm{H}$ - or J-aggregation does not affect appreciably the excited state deactivation pathways or the triplet lifetimes.

In crystalline $\mathrm{Cz}$, because of the small values of exciton couplings with respect to the reorganisation energies, the excited states are localised $\left(1.0 \times 10^{-3} \mathrm{eV}<J_{i j}^{\mathrm{S}}<2.3 \times\right.$ $10^{-2} \mathrm{eV}, \lambda=0.246 \mathrm{eV}$ for $\mathrm{S}_{1}$ ). This is in line with the behaviour of most semiconducting organic crystals. ${ }^{21,39,61}$ Light-activated mechanisms centred on molecular $\mathrm{Cz}$ initiate a cascade of processes starting with the initial population of singlet states, which rapidly decay to $S_{1}$ or the triplet manifold. These processes are essential to describe the excited state properties. This is supported by the excellent agreement between the predicted values of quantum yields only based on molecule centred processes and the experimental ones (0.76 (0.55) vs. 0.78). Our estimation of the intersystem crossing rates is also in excellent agreement with the experimental value, highlighting that ISC is the main nonradiative decay process depleting the singlet population.

Triplet states are clearly localised on independent $\mathrm{Cz}$ molecules and their main transport mechanism is the Dexter energy transfer. Based on the estimation of hopping rates, we analysed possible singlet exciton and triplet transfer pathways. In the $\mathrm{Cz}$ crystal, exciton transport is very effective along $\mathrm{C}$ dimers, with a $\pi$-stacking structure. Because of the less effective couplings between triplet and singlet states, the Dexter energy transport involving triplets is slower. However, due to the long lifetimes of triplets, their diffusion lengths are longer. Bimolecular processes such as triplet-triplet annihilation are limited by the concentration of triplets. In line with experimental observations, our calculations indicate that delayed fluorescence can occur using low powers. ${ }^{20}$

We analyse the effect of isomeric defects and the formation of charge transfer states in $\mathrm{Cz}$ doped with $\mathrm{Bd}$. Our results are in line with the experimental observations by Liu et al. ${ }^{20}$ Triplets (and singlets) can travel to the Bd defects or they can be directly excited at the molecular $\mathrm{Cz}-\mathrm{Bd}$ junctions. The $\left(\mathrm{Cz}^{-} \mathrm{Bd}^{+}\right)$states are appreciably more stable than the $\left(\mathrm{Cz}^{-} \mathrm{Cz}^{+}\right)$states. Because of this, charge separation occurs at the $\mathrm{Cz}-\mathrm{Bd}$ molecular interfaces generating $\mathrm{Cz}^{-}$polarons. These calculations indicate that the presence of impurities, even at small concentrations, is essential to allow the formation of charge separated states. The effective charge transfer $\left(10^{14} \mathrm{~s}^{-1}\right)$ from $\mathrm{Cz}^{-}$to neutral $\mathrm{Cz}$ helps keep the excited states alive increasing the lifetimes in commercial or doped samples of crystalline Cz.

We hope that our results contribute to a better understanding of light-activated mechanisms in crystalline $\mathrm{Cz}$ and the role of isomeric defects on the long-lived excited states. Controlling the functionality of organic materials by isomeric doping seems to be a promising strategy with plenty of applications in the field of optoelectronics. ${ }^{20}$ Our simulations provide a plausible explanation for the generation of charge-separated states in line with the experimental observations. In a recent study, Ding et al. explored the concept of defect incorporation in crystals of 1-(4bromophenyl)- $1 H$-imidazole (1BBI) achieving a yield of $74.2 \%$ with a lifetime of $430 \mathrm{~ms}$ for one of the bicomponent systems. ${ }^{22}$ This research shows that this phenomenon is not limited to $\mathrm{Cz}$ highlighting the potential of the use of organic impurities to achieve efficient RTP systems. We hope our work can help support further advances in this exciting field.

\section{Conflicts of interest}

There are no conflicts to declare.

\section{Acknowledgements}

This research has been supported by the EPSRC (EP/R029385/1) and Leverhulme Trust (RPG-2019-122). We utilized Queen Mary's Apocrita HPC facility, supported by QMUL Research-IT and the ARCHER UK National Supercomputing Service (EP/ L000202/1) via the Materials Chemistry Consortium and the Molecular Modelling Hub for computational resources, MMM Hub, which is partially funded by EPSRC (EP/T022213/1). The authors acknowledge the support from the School of Biological and Chemical Sciences at the Queen Mary University of London.

\section{References}

1 J. Mei, N. L. Leung, R. T. Kwok, J. W. Lam and B. Z. Tang, Chem. Rev., 2015, 115, 11718-11940.

2 S. Hirata, Adv. Opt. Mater., 2017, 5, 1700116.

3 Y. Chen, J. W. Lam, R. T. Kwok, B. Liu and B. Z. Tang, Mater. Horiz., 2019, 6, 428-433.

4 R. Crespo-Otero, Q. Li and L. Blancafort, Chem. - Asian J., 2019, 14, 700-714.

5 J. Li and K. Pu, Chem. Soc. Rev., 2019, 48, 38-71.

6 I. Bergenti, V. Dediu, M. Prezioso and A. Riminucci, Philos. Trans. R. Soc., A, 2011, 369, 3054-3068.

7 J. Gierschner, S. Varghese and S. Y. Park, Adv. Opt. Mater., 2016, 4, 348-364.

8 W. Jia, Q. Wang, H. Shi, Z. An and W. Huang, Chem. - Eur. J., 2020, 26, 4437-4448. 
9 Y. Gong, L. Zhao, Q. Peng, D. Fan, W. Z. Yuan, Y. Zhang and B. Z. Tang, Chem. Sci., 2015, 6, 4438-4444.

10 T. Zhang, H. Gao, A. Lv, Z. Wang, Y. Gong, D. Ding, H. Ma, Y. Zhang and W. Z. Yuan, J. Mater. Chem. C, 2019, 7, 9095-9101.

11 X. Wang, H. Ma, M. Gu, C. Lin, N. Gan, Z. Xie, H. Wang, L. Bian, L. Fu, S. Cai, Z. Chi, W. Yao, Z. An, H. Shi and W. Huang, Chem. Mater., 2019, 31, 5584-5591.

12 K. Jiang, L. Zhang, J. Lu, C. Xu, C. Cai and H. Lin, Angew. Chem., Int. Ed., 2016, 55, 7231-7235.

13 Y. Su, Y. Zhang, Z. Wang, W. Gao, P. Jia, D. Zhang, C. Yang, Y. Li and Y. Zhao, Angew. Chem., Int. Ed., 2020, 59, 9967-9971.

14 X. Zhen, Y. Tao, Z. An, P. Chen, C. Xu, R. Chen, W. Huang and K. Pu, Adv. Mater., 2017, 29, 1606665.

15 Kenry, C. Chen and B. Liu, Nat. Commun., 2019, 10, 1-15.

16 H. A. Collins, M. Khurana, E. H. Moriyama, A. Mariampillai, E. Dahlstedt, M. Balaz, M. K. Kuimova, M. Drobizhev, V. X. Yang, D. Phillips, A. Rebane, B. C. Wilson and H. L. Anderson, Nat. Photonics, 2008, 2, 420-424.

17 R. Kabe, N. Notsuka, K. Yoshida and C. Adachi, Adv. Mater., 2016, 28, 655-660.

18 W. Zhao, T. S. Cheung, N. Jiang, W. Huang, J. W. Lam, X. Zhang, Z. He and B. Z. Tang, Nat. Commun., 2019, 10, 1595.

19 C. Sun, X. Ran, X. Wang, Z. Cheng, Q. Wu, S. Cai, L. Gu, N. Gan, H. Shi, Z. An, H. Shi and W. Huang, J. Phys. Chem. Lett., 2018, 9, 335-339.

20 C. Chen, Z. Chi, K. C. Chong, A. S. Batsanov, Z. Yang, Z. Mao, Z. Yang and B. Liu, Nat. Mater., 2020, 4-10.

21 A. Troisi, Chem. Soc. Rev., 2011, 40, 2347.

22 B. Ding, L. Ma, Z. Huang, X. Ma and H. Tian, Sci. Adv., 2021, 7, eabf9668.

23 P. Giannozzi, S. Baroni, N. Bonini, M. Calandra, R. Car, C. Cavazzoni, D. Ceresoli, G. L. Chiarotti, M. Cococcioni, I. Dabo, A. Dal Corso, S. De Gironcoli, S. Fabris, G. Fratesi, R. Gebauer, U. Gerstmann, C. Gougoussis, A. Kokalj, M. Lazzeri, L. Martin-Samos, N. Marzari, F. Mauri, R. Mazzarello, S. Paolini, A. Pasquarello, L. Paulatto, C. Sbraccia, S. Scandolo, G. Sclauzero, A. P. Seitsonen, A. Smogunov, P. Umari and R. M. Wentzcovitch, J. Phys.: Condens. Matter, 2009, 21, 395502.

24 M. Rivera, M. Dommett and R. Crespo-Otero, J. Chem. Theory Comput., 2019, 15, 2504-2516.

25 M. Rivera, M. Dommett, A. Sidat, W. Rahim and R. CrespoOtero, J. Comput. Chem., 2020, 41, 1045-1058.

26 M. J. Frisch, G. W. Trucks, H. B. Schlegel, G. E. Scuseria, M. A. Robb, J. R. Cheeseman, G. Scalmani, V. Barone, G. A. Petersson, H. Nakatsuji, X. Li, M. Caricato, A. V. Marenich, J. Bloino, B. G. Janesko, R. Gomperts, B. Mennucci, H. P. Hratchian, J. V. Ortiz, A. F. Izmaylov, J. L. Sonnenberg, D. Williams-Young, F. Ding, F. Lipparini, F. Egidi, J. Goings, B. Peng, A. Petrone, T. Henderson, D. Ranasinghe, V. G. Zakrzewski, J. Gao, N. Rega, G. Zheng, W. Liang, M. Hada, M. Ehara, K. Toyota, R. Fukuda, J. Hasegawa, M. Ishida, T. Nakajima,
Y. Honda, O. Kitao, H. Nakai, T. Vreven, K. Throssell, J. A. Montgomery, Jr., J. E. Peralta, F. Ogliaro, M. J. Bearpark, J. J. Heyd, E. N. Brothers, K. N. Kudin, V. N. Staroverov, T. A. Keith, R. Kobayashi, J. Normand, K. Raghavachari, A. P. Rendell, J. C. Burant, S. S. Iyengar, J. Tomasi, M. Cossi, J. M. Millam, M. Klene, C. Adamo, R. Cammi, J. W. Ochterski, R. L. Martin, K. Morokuma, O. Farkas, J. B. Foresman and D. J. Fox, Gaussian $\sim 16$ Revision A.03, Gaussian Inc., Wallingford CT, 2016.

27 B. Aradi, B. Hourahine and T. Frauenheim, J. Phys. Chem. A, 2007, 111, 5678-5684.

28 B. G. Levine, J. D. Coe and T. J. Martínez, J. Phys. Chem. B, 2008, 112, 405-413.

29 G. C. Schatz and M. A. Ratner, Quantum mechanics in chemistry, 1998.

30 W. J. Kusto and J. W. Rohleder, Mol. Cryst. Liq. Cryst., 1979, 55, 151-161.

31 G. Baryshnikov, B. Minaev and H. Ågren, Chem. Rev., 2017, 117, 6500-6537.

32 H. Ågren, O. Vahtras and B. Minaev, Adv. Quantum Chem., 1996, 27, 71-162.

33 B. Minaev, G. Baryshnikov and H. Agren, Phys. Chem. Chem. Phys., 2014, 16, 1719-1758.

34 O. Vahtras, H. Ågren, P. Jørgensen, H. J. A. Jensen, T. Helgaker and J. Olsen, J. Chem. Phys., 1992, 97, 9178-9187.

35 K. Aidas, C. Angeli, K. L. Bak, V. Bakken, R. Bast, L. Boman, O. Christiansen, R. Cimiraglia, S. Coriani, P. Dahle, E. K. Dalskov, U. Ekström, T. Enevoldsen, J. J. Eriksen, P. Ettenhuber, B. Fernández, L. Ferrighi, H. Fliegl, L. Frediani, K. Hald, A. Halkier, C. Hättig, H. Heiberg, T. Helgaker, A. C. Hennum, H. Hettema, E. Hjertenæs, S. Høst, I.-M. Høyvik, M. F. Iozzi, B. Jansík, H. J. Aa Jensen, D. Jonsson, P. Jørgensen, J. Kauczor, S. Kirpekar, T. Kjærgaard, W. Klopper, S. Knecht, R. Kobayashi, H. Koch, J. Kongsted, A. Krapp, K. Kristensen, A. Ligabue, O. B. Lutnæs, J. I. Melo, K. V. Mikkelsen, R. H. Myhre, C. Neiss, C. B. Nielsen, P. Norman, J. Olsen, J. M. H. Olsen, A. Osted, M. J. Packer, F. Pawlowski, T. B. Pedersen, P. F. Provasi, S. Reine, Z. Rinkevicius, T. A. Ruden, K. Ruud, V. V. Rybkin, P. Sałek, C. C. M. Samson, A. S. de Merás, T. Saue, S. P. A. Sauer, B. Schimmelpfennig, K. Sneskov, A. H. Steindal, K. O. Sylvester-Hvid, P. R. Taylor, A. M. Teale, E. I. Tellgren, D. P. Tew, A. J. Thorvaldsen, L. Thøgersen, O. Vahtras, M. A. Watson, D. J. D. Wilson, M. Ziolkowski and H. Ågren, WIREs Comput. Mol. Sci., 2014, 4, 269-284.

36 R. Liu, X. Gao, M. Barbatti, J. Jiang and G. Zhang, J. Phys. Chem. Lett., 2019, 10, 1388-1393.

37 X. Gao, S. Bai, D. Fazzi, T. Niehaus, M. Barbatti and W. Thiel, J. Chem. Theory Comput., 2017, 13, 515-524.

38 R. P. Fornari, J. Aragó and A. Troisi, J. Chem. Phys., 2015, 142, 184105.

39 J. Aragó and A. Troisi, Adv. Funct. Mater., 2016, 26, 2316-2325.

40 J. R. Reimers, J. Chem. Phys., 2001, 115, 9103-9109. 
41 A. R. Auty, A. C. Jones and D. Phillips, Chem. Phys., 1986, 103, 163-182.

42 S. M. Bonesi and R. Erra-Balsells, J. Lumin., 2001, 93, 51-74.

43 Y. Shao, Z. Gan, E. Epifanovsky, A. T. Gilbert, M. Wormit, J. Kussmann, A. W. Lange, A. Behn, J. Deng, X. Feng, D. Ghosh, M. Goldey, P. R. Horn, L. D. Jacobson, I. Kaliman, R. Z. Khaliullin, T. Kuś, A. Landau, J. Liu, E. I. Proynov, Y. M. Rhee, R. M. Richard, M. A. Rohrdanz, R. P. Steele, E. J. Sundstrom, H. L. Woodcock, P. M. Zimmerman, D. Zuev, B. Albrecht, E. Alguire, B. Austin, G. J. O. Beran, Y. A. Bernard, E. Berquist, K. Brandhorst, K. B. Bravaya, S. T. Brown, D. Casanova, C.-M. Chang, Y. Chen, S. H. Chien, K. D. Closser, D. L. Crittenden, M. Diedenhofen, R. A. DiStasio, H. Do, A. D. Dutoi, R. G. Edgar, S. Fatehi, L. Fusti-Molnar, A. Ghysels, A. Golubeva-Zadorozhnaya, J. Gomes, M. W. Hanson-Heine, P. H. Harbach, A. W. Hauser, E. G. Hohenstein, Z. C. Holden, T.-C. Jagau, H. Ji, B. Kaduk, K. Khistyaev, J. Kim, J. Kim, R. A. King, P. Klunzinger, D. Kosenkov, T. Kowalczyk, C. M. Krauter, K. U. Lao, A. D. Laurent, K. V. Lawler, S. V. Levchenko, C. Y. Lin, F. Liu, E. Livshits, R. C. Lochan, A. Luenser, P. Manohar, S. F. Manzer, S.-P. Mao, N. Mardirossian, A. V. Marenich, S. A. Maurer, N. J. Mayhall, E. Neuscamman, C. M. Oana, R. Olivares-Amaya, D. P. O’Neill, J. A. Parkhill, T. M. Perrine, R. Peverati, A. Prociuk, D. R. Rehn, E. Rosta, N. J. Russ, S. M. Sharada, S. Sharma, D. W. Small, A. Sodt, T. Stein, D. Stück, Y.-C. Su, A. J. Thom, T. Tsuchimochi, V. Vanovschi, L. Vogt, O. Vydrov, T. Wang, M. A. Watson, J. Wenzel, A. White, C. F. Williams, J. Yang, S. Yeganeh, S. R. Yost, Z.-Q. You, I. Y. Zhang, X. Zhang, Y. Zhao, B. R. Brooks, G. K. Chan, D. M. Chipman, C. J. Cramer, W. A. Goddard, M. S. Gordon, W. J. Hehre, A. Klamt, H. F. Schaefer, M. W. Schmidt, C. D. Sherrill, D. G. Truhlar, A. Warshel, X. Xu, A. AspuruGuzik, R. Baer, A. T. Bell, N. A. Besley, J.-D. Chai, A. Dreuw, B. D. Dunietz, T. R. Furlani, S. R. Gwaltney, C.-P. Hsu, Y. Jung, J. Kong, D. S. Lambrecht, W. Liang, C. Ochsenfeld, V. A. Rassolov, L. V. Slipchenko,
J. E. Subotnik, T. Van Voorhis, J. M. Herbert, A. I. Krylov, P. M. Gill and M. Head-Gordon, Mol. Phys., 2015, 113, 184-215.

44 TURBOMOLE V7.0 2015, a development of University of Karlsruhe and Forschungszentrum Karlsruhe GmbH, 1989-2007, TURBOMOLE GmbH, since 2007; available from http://www. turbomole.com.

45 R. C. Powell and Z. G. Soos, J. Lumin., 1975, 11, 1-45.

46 V. Stehr, R. F. Fink, B. Engels, J. Pflaum and C. Deibel, J. Chem. Theory Comput., 2014, 10, 1242-1255.

47 Y. Gu, K. Wang, Y. Dai, G. Xiao, Y. Ma, Y. Qiao and B. Zou, J. Phys. Chem. Lett., 2017, 8, 4191-4196.

48 C. M. Marian, Wiley Interdiscip. Rev.: Comput. Mol. Sci., 2012, 2, 187-203.

49 H. Ma, Q. Peng, Z. An, W. Huang and Z. Shuai, J. Am. Chem. Soc., 2019, 141, 1010-1015.

50 H. J. Haink and J. R. Huber, J. Mol. Spectrosc., 1976, 60, 31-42.

51 Z. He, W. Zhao, J. W. Lam, Q. Peng, H. Ma, G. Liang, Z. Shuai and B. Z. Tang, Nat. Commun., 2017, 8, 1-8.

52 Z. An, C. Zheng, Y. Tao, R. Chen, H. Shi, T. Chen, Z. Wang, H. Li, R. Deng, X. Liu and W. Huang, Nat. Mater., 2015, 14, 685-690.

53 M. Kasha, H. R. Rawls and M. A. El-Bayoumi, Pure Appl. Chem., 1965, 11, 371-392.

54 N. J. Hestand and F. C. Spano, Chem. Rev., 2018, 118, 7069-7163.

55 H. Haink and J. Huber, J. Mol. Spectrosc., 1976, 60, 31-42.

56 O. V. Mikhnenko, P. W. M. Blom and T.-Q. Nguyen, Energy Environ. Sci., 2015, 8, 1867-1888.

57 S. R. Yost, E. Hontz, S. Yeganeh and T. Van Voorhis, J. Phys. Chem. C, 2012, 116, 17369-17377.

58 V. Ern, Phys. Rev. Lett., 1969, 22, 343-345.

59 S. Hirata, H. Hara and I. Bhattacharjee, J. Chem. Phys., 2020, 124, 25121-25132.

60 A. Monguzzi, J. Mezyk, F. Scotognella, R. Tubino and F. Meinardi, Phys. Rev. B: Condens. Matter Mater. Phys., 2008, 78, 195112.

61 J. Aragó and A. Troisi, Phys. Rev. Lett., 2015, 114, 026402. 